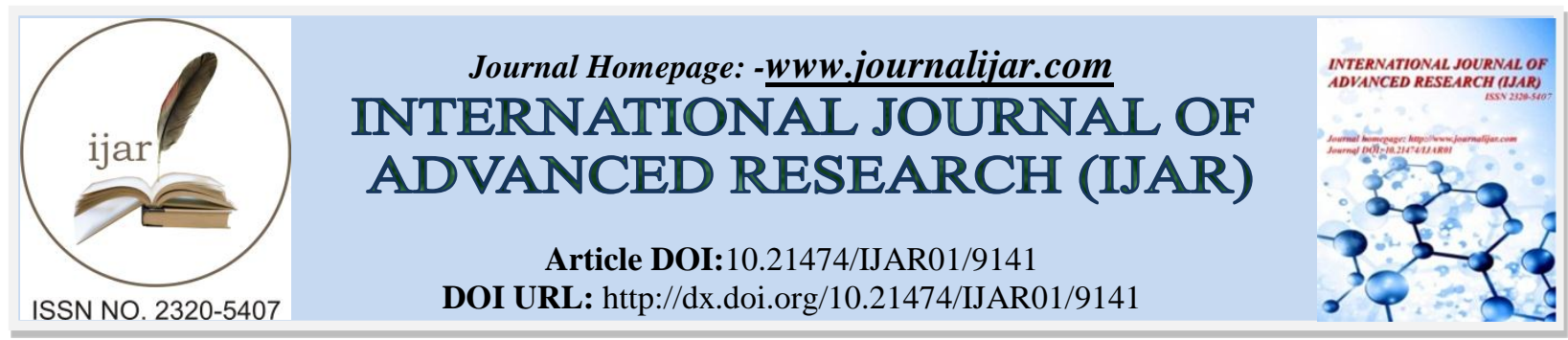

RESEARCH ARTICLE

\title{
NOMENCLATURE AND DESCRIPTIVE ANATOMY OF THE OLFACTORY BULB FISSURE AND DEFINITION OF THE OLFACTORY BULB DIMENSIONS IN DOGS USING IN VIVO MRI.
}

\section{A.k. Hussein ${ }^{1}$, M.Sullivan ${ }^{2}$ And J. Penderis ${ }^{2}$.}

1. College of veterinary medicine, university of Baghdad.

2. School of veterinary medicine, college of medical, veterinary and life sciences, university of glasgow, uk.

\section{Manuscript Info}

Manuscript History

Received: 24 March 2019

Final Accepted: 26 April 2019

Published: May 2019

Key words:-

MRI, Dogs, Olfactory bulb, Fissure, Anatomical.

\section{Abstract}

Olfaction is one of the most important sensory functions in dogs, and one which strongly influences behaviour, including feeding, social interaction and reproduction. The olfactory bulbs are situated within the ethmoidal fossae of the cranial cavity, comprising part of the rostral cranial fossa and are bounded cranially by the cribriform plate of the ethmoidal bone. The nasal aspect of the cribriform plate is continuous with the ethmoidal turbinates, which are lined by the olfactory epithelium. The anatomical position of the olfactory bulb in relation to the brain has been shown to vary significantly with the cephalic index, becoming progressively more ventrally orientated with increasing degrees of brachycephalia. Correct identification of the olfactory bulbs and their related ethmoidal turbinates are also important in a number of neurological conditions, including neoplasia, hydrocephalus (with dilation of the olfactory bulb recess in obstructive hydrocephalus) and for harvesting of olfactory ensheathing cells from the nasal epithelium. A review of the anatomical literature from 1881 to 2012 describes a variety of terms for the grooves that separate the olfactory lobes from the rest of the brain; however there is no term to describe the groove separating the olfactory bulb from the brain. The aim of this study was to describe this anatomical feature by in vivo MRI and suggest olfactory bulb fissure as an appropriate descriptive term.

MRI studies from 261 individual dogs, representing a wide spectrum of breeds, were reviewed to describe the anatomy of the olfactory bulb fissure. Dorsal and midline-sagittal plane T1- and T2-weighted images were reviewed for each case and a single image was selected from each of these imaging planes and sequences for each dog. All four images were not available in all dogs due to variation in the MRI studies and a total of 639 MR images were reviewed.

The olfactory bulb fissure could be identified in $83 \%$ and $97 \%$ of T1and T2-weighted midline-sagittal plane MR images respectively, and appeared as a line sloping from rostrodorsal to caudoventral, situated between the olfactory bulb and the frontal cortex. On dorsal plane MR images it could be identified in $86 \%$ and $95 \%$ of T1- and T2-weighted images respectively, and was evident as a line separating the olfactory bulb and frontal cortex, extending from rostromedial to caudolateral. In T1-weighted MR images the olfactory bulb fissure appeared as a 
hypointense line, while in T2-weighted images it appeared as a hyperintense line, confluent with the subarachnoid cerebrospinal fluid filled spaces. The olfactory blub fissure is proposed as a suitable descriptive term and can reliably be identified in the majority of T1and T2-weighted dorsal and midline-sagittal plane MRI sequences. The olfactory bulb fissure is useful to define the position of the cribriform plate and to determine the olfactory bulb angulation, which has previously been reported to be an accurate and objective measure of the degree of brachycephalia in dogs.

Copy Right, IJAR, 2019,. All rights reserved.

\section{Introduction:-}

The gross anatomic appearance of the olfactory bulb is well recognised, and to a certain extent the magnetic resonance imaging (MRI) appearance. However, there is little published work attempting to determine the dimensions of this portion of the brain on MRI.

In man, Warwick and Williams (1973) in Gray's Anatomy defined the olfactory bulb as "a compressed, oval mass which is located upper to the medial margin of the orbital plate of frontal bone near the lateral margin of the cribriform plate".

In the veterinary field, a variety of definitions have been applied. Beitz and Fletcher (1993) described the olfactory bulb in dogs as the first component of the basal portion of the rhinencephalon, and as the rostral growth of the olfactory peduncle where the olfactory nerves terminate. Alternatively, the olfactory bulb has been considered to be the most rostral portion of the olfactory region, composed of an accumulation of olfactory nerve fibres from the vomeronasal part at the inner surface of the cribriform plate (Smith, 1999).

Generally, the rostral part of the cranial fossa is defined as the area of the cranial cavity that extends from the cribriform plate to the level of the optic canal (Anderson et al. 1994; Smith, 1999; Budras et al. 2002). The rostral cranial fossa extends rostrally to include the ethmoidal fossa and caudally is bounded by the middle cranial fossa (Evans, 1993). The rostral cranial fossa is a much narrower than the middle and caudal parts of the cranial fossa (Anderson et al. 1994; Smith, 1999; Budras et al. 2002). Evans (1993) referred to the ethmoidal fossa as a deep rostral continuity of the rostral parts of the cranial fossa. The rostral fossa supports the olfactory bulb, tract and other parts of the frontal lobes (Evans, 1993; Anderson et al. 1994; Smith, 1999). In 1883, Langley defined the frontal lobe as "the lobe which includes the sub-orbital lobe and the part of the anterior limb of the sigmoidal gyrus which lies medially of a line drawn in a sagittal direction from the anterior end of the crucial fissure to the supraorbital fissure" . Furthermore, Ferrier (1888), (cited by Bianchi 1985), referred to the area rostral to the sigmoid gyrus as the frontal lobes in dogs and cats. On MRI, the frontal cortex was defined as extending from the anterior pole of the olfactory bulb to the anterior cruciate sulcus (Tapp et al. 2004) (Figure-3).

In 1883, (Langley, 1883) described an intra-olfactory fissure as a groove, which is shallow or missed at the posterior portion of the olfactory lobe, yet used the term inter-olfactory fissure in an accompanying diagram to describe the same feature. (Anderson et al, 1994), named the olfactory sulcus as the groove separating the olfactory lobe from the rest of the brain on lateral aspect in dogs. This definition has also been used in man (Gottfried and Zald, 2005). However, in the same species, the olfactory fissure was used to describe the groove between the middle turbinate and the septum in the nasal cavity (Lee et al., 2007). The olfactory recess has been considered as a part of the cranial cavity by (Weidenreich, 1940). The same term is considered to be located outside the cranium, in the nasal cavity, by others (Craven et al., 2009)). The groove between the olfactory peduncle and the olfactory bulb was given the name sulcus limitans bulbi olfactorii in Nomina Anatomica Veterinaria (Schaller, 1992). Consequently, there appears to be a lack of consensus on the application of anatomical terms.

Grooves which separate one part or more of the olfactory lobe from the rest of the brain have been reported since the nineteen century. Gervais (1870) described the rhinal fissure as the groove that lies above the olfactory lobe and separates it from the uncinate region (cited by (Langley, 1883). Similarly Krueg in 1880 defined the anterior 
extension of the rhinal fissure as the olfactory fissure, which separates the olfactory tract from the brain cortex (cited by (Langley, 1883).

In 1873, Wilder called this olfactory fissure the ecto-rhinal fissure (cited by (Wilder, 1880). Further through dissection of the cat brains to identify the structures of the brain used the term olfactory fissure to describe the fissure where the olfactory lobe was lodged (Wilder, 1880).

De Lahunta (1983) and De Lahunta \& Glass (2009) reported that the olfactory nerves (cranial nerve I) penetrate the cribriform plate to reach the olfactory bulb. The olfactory bulb has been clearly identified in the dorsal, mid-sagittal and transverse planes of MR images in different breeds of dogs (Kraft et al., 1989b;Leigh et al., 2008d;Fletcher, 2010). CT has also been used to identify the brain anatomy of dogs (Kaufman et al., 1981; Assheuer and Sager, 1997). However, CT is unable to provide the level of detail that can be obtained from MRI.

The olfactory bulb is described in dogs as the first component of the basal portion of the rhinencephalon, and as the rostral extension of the olfactory peduncle, where the olfactory nerves terminate. Additionally, the olfactory bulb may be considered to be the most rostral portion of the olfactory region, composed of an accumulation of olfactory nerve fibres adjacent to the inner surface of the cribriform plate (Figure-3) (Beitz and Fletcher, 1993). In man, Warwick and Williams (1973) in Gray's Anatomy defined the olfactory bulb as "a compressed, oval mass which is located upper to the medial margin of the orbital plate of frontal bone near the lateral margin of the cribriform plate".

The aim of this study was to determine the olfactory bulb fissure using MRI technique.

\section{Materials and Methods:- \\ Animals}

639 images from 261 cases of different breeds, were all client-owned pet dogs presented to the Small Animal Hospital, University of Glasgow between 2007 and 201, have been used to identify the olfactory bulb fissure. T1\&T2 sequences of both Mid-sagittal and dorsal planes have been tested to determine the olfactory bulb fissure. The olfactory bulb fissure has been defined as the groove which separates the olfactory bulb from the rest of the brain. The routine sequences described above included the relevant parts of the head required for the purposes of this study.

Case history was gained from each animal and the MR images were all part of the normal clinical investigation in that particular animal and no additional procedures were performed for the purposes of this study. Ethical approval was granted through the local Ethics and Welfare Committee.

MRI was performed using a 1.5 Tesla MRI unit (Siemens Magnetom Essenza, Siemens Medical Solutions, Camberley, UK). All images were examined using eFilm (Workstation 3.0 is a widely used DICOM viewer, and is a trademark of Merge Healthcare).

\section{Results:}

\section{Identification and descriptive appearance of the olfactory bulb fissure}

The olfactory bulb fissure was identified and defined on fresh and formalin fixed heads (Figures $1 \& 2$ ) as well as on T1-weighted and T2-weighted MR images (Figures 3\&4) in the midline sagittal and dorsal planes. 328 T1 and T2weighted midline sagittal images were available for review and from these the olfactory bulb was identified in 309 images (94\%). It appears as a hypointense line on $\mathrm{T} 1 \mathrm{w}$ and hyperintense line on $\mathrm{T} 2 \mathrm{w}$. Within this group of 309 midline sagittal images, the olfactory bulb fissure was recognised in $97 \%$ of the T2-weighted images, and in $83 \%$ the T1-weighted images. The olfactory bulb fissure was identified in 282 images from the total 311 dorsal plane images available (91\%). Within these 282 plane images, the olfactory bulb fissure was identified in $86 \%$ of the available $\mathrm{T} 1$-weighted images and $95 \%$ of the $\mathrm{T} 2$-weighted images.

The olfactory bulb fissure was more readily identified on T2-weighted than T1-weighted MR images (96\% and 85\% respectively (Table 1 and Figures $3 \& 4$ ).

\begin{tabular}{|l|l|l|l|}
\hline & Midline sagittal & Dorsal & Total \\
\hline T1 & $83 \%(59 / 71)$ & $86 \%(127 / 147)$ & $85 \%(186 / 218)$ \\
\hline
\end{tabular}




\begin{tabular}{|l|l|l|l|}
\hline T2 & $97 \%(250 / 257)$ & $95 \%(155 / 164)$ & $96 \%(405 / 421)$ \\
\hline Total & $94 \%(309 / 328)$ & $91 \%(282 / 311)$ & $93 \%(591 / 639)$ \\
\hline
\end{tabular}

Table 1:-The total number of MR images reviewed and the proportion and percentage of these where the olfactory bulb fissure could be recognised on $\mathrm{T} 1$ and $\mathrm{T} 2$-weighted images in the midline sagittal and dorsal planes

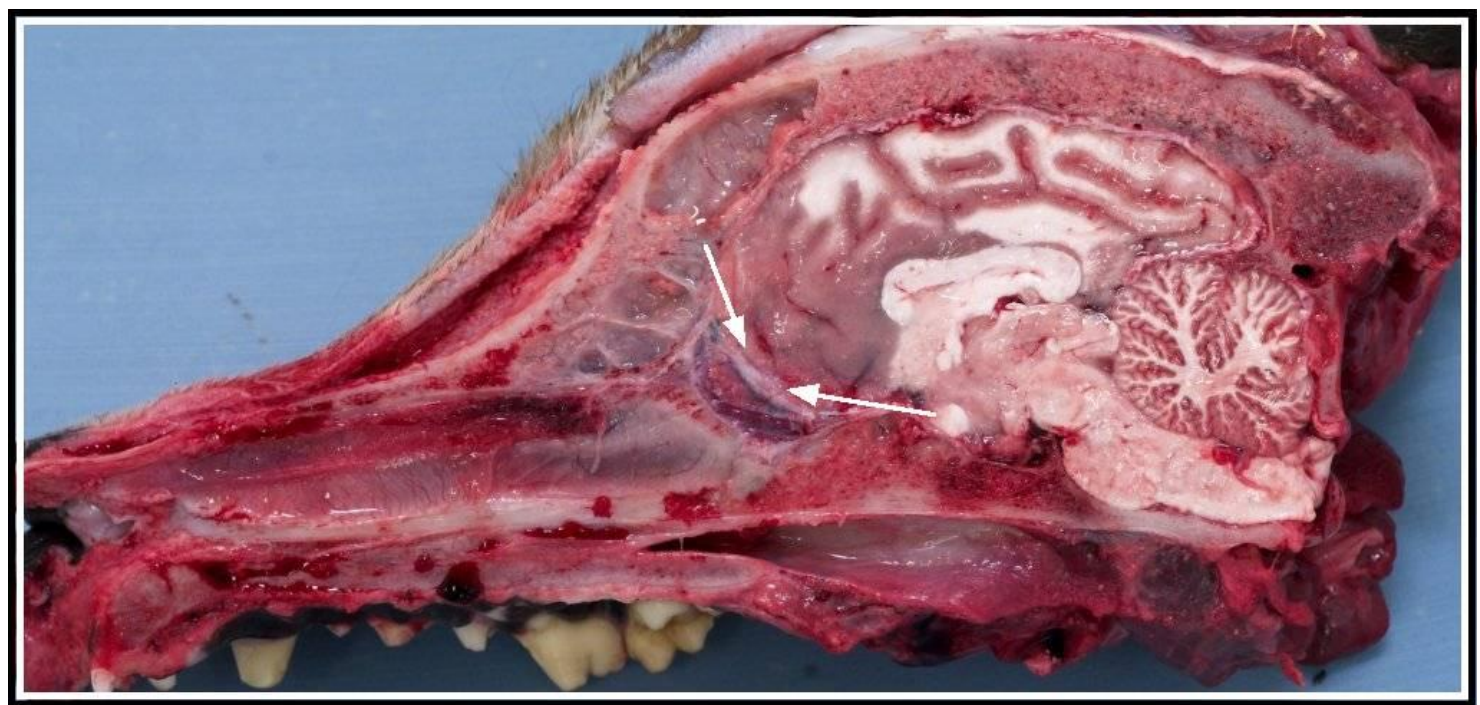

Figure 1:-Fresh gross midline section through the canine head allowing identification of the olfactory bulb fissure (white arrows) following gross dissection

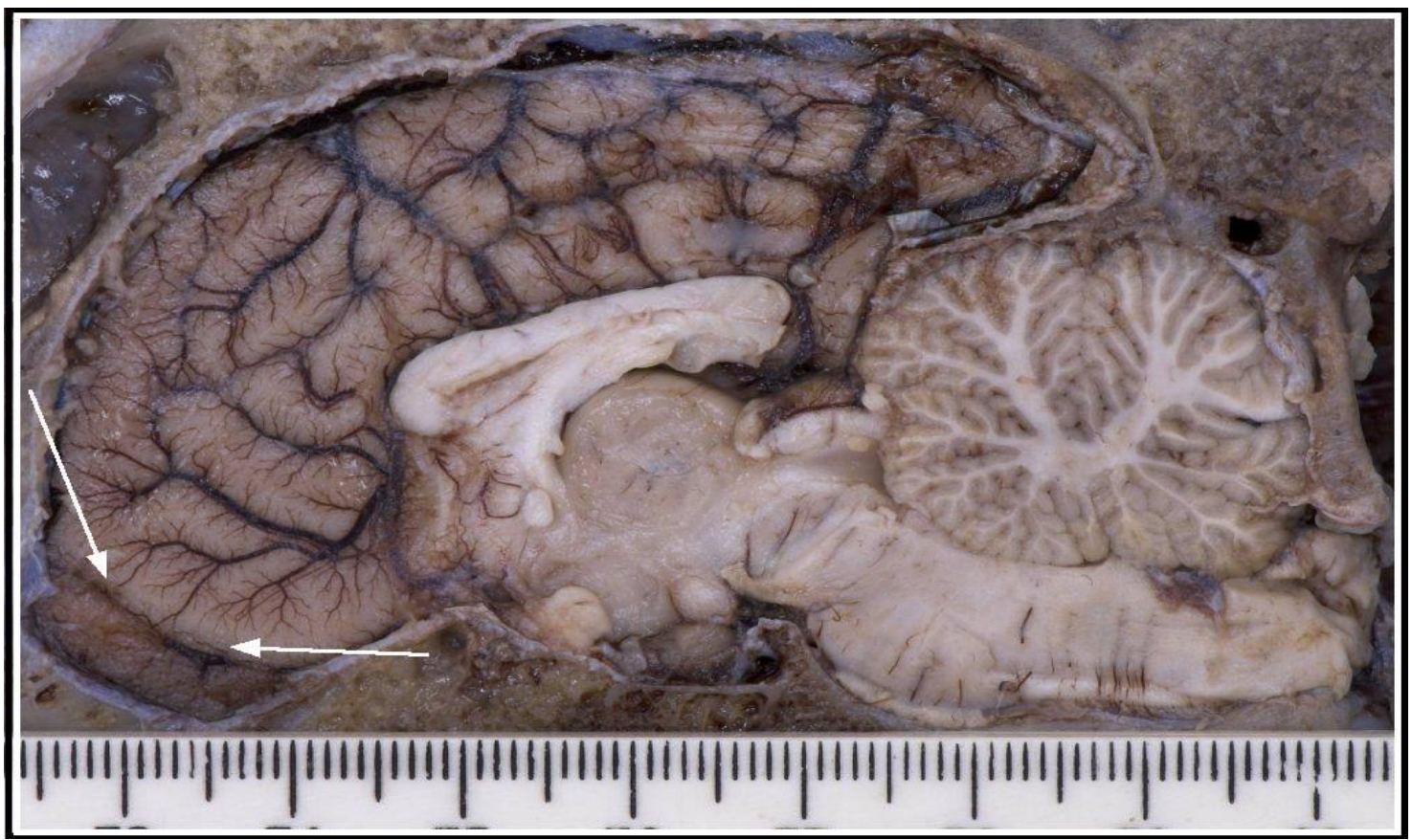

Figure 2:-Gross midline formalin fixed section through the canine head identifying the olfactory bulb fissure (white arrows) following immersion in $10 \%$ formalin for seven days 


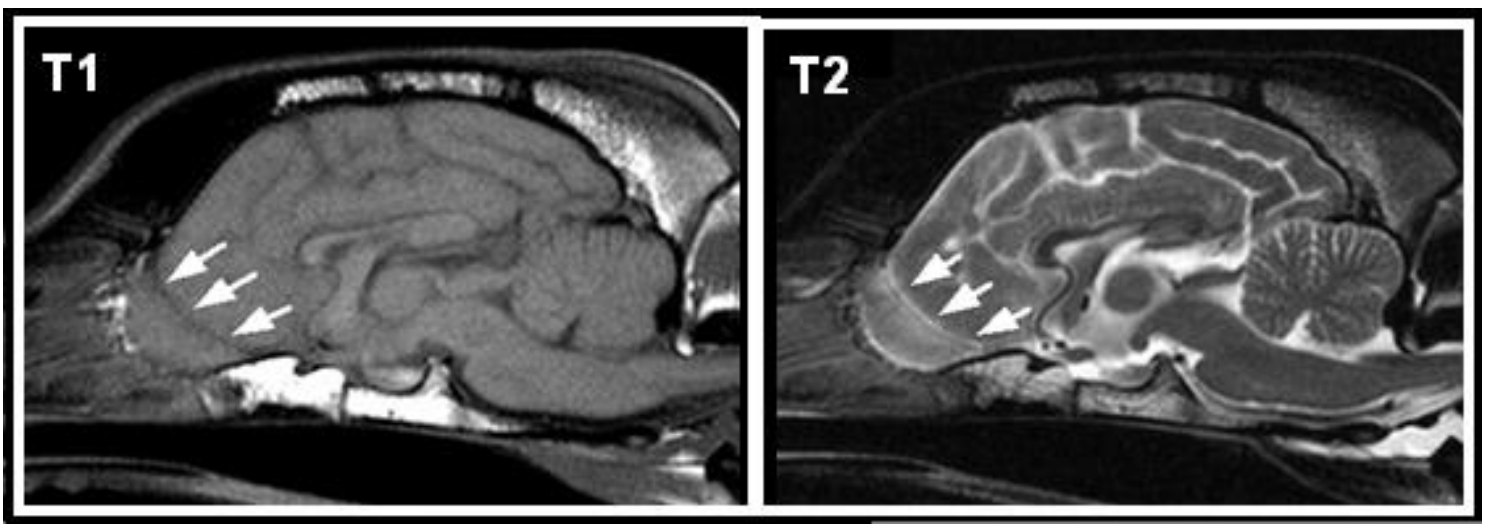

Figure 3:-The olfactory bulb fissure (arrows), defined as the fissure that separates the olfactory bulb from the rest of the brain, as seen on midline sagittal plane T1 and T2-weighted MR images

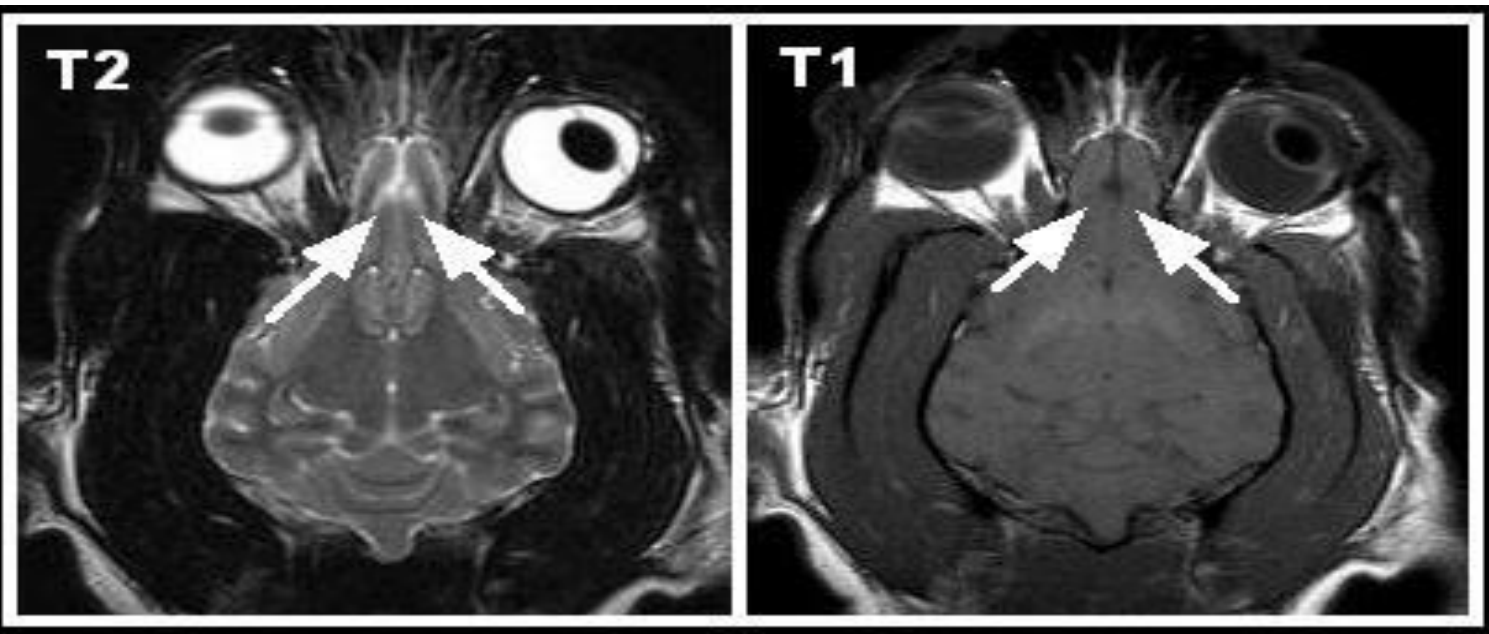

Figure 4:-Dorsal plane T2 and T1-weighted MR images demonstrating the appearance of the olfactory bulb fissure, defined as a groove separating the olfactory bulb from the rest of the brain (arrows)

\section{Discussion:-}

Anatomical features of the brain have been represented grossly (Beitz and Fletcher, 1993) and by using MRI (Kraft et al., 1989; Assheuer and Sager, 1997; Leigh et al., 2008). Computed tomography (George and Smallwood, 1992; Assheuer and Sager, 1997), xeroradiographs and anatomical sections for the brain have also been performed (George and Smallwood, 1992). Although computed tomography gives the best quality for imaging the cribriform plate (Berry and Koblik, 1990) . MR images of the olfactory bulb and the cribriform plate have been shown to be of a good quality (Dhaliwal et al., 2004)

Different names are given to grooves separate the olfactory bulb from various parts of the brain. However, the groove which separates the olfactory bulb from the rest of the brain has no name yet. Thence a term olfactory bulb fissure was given to the groove which separates the olfactory bulb from the whole brain when after identifying it grossly and 90\% of T1\&T2-weighted MRI scans of dorsal and midline sagittal planes. This ratio may, in part, be explained by the high visualisation of the soft tissue which can be identified by using MRI technique. However, delineated of the olfactory bulb border was clearer in dorsal plane of MRI images than sagittal in a group of terriers and working dogs (Drees et al., 2009). It was important to define that groove anatomically and by MRI technique for future work.

\section{References:-}

1. Beitz, A. and Fletcher, TF. (1993) The brain 28. In: Miller, ME., (Ed.) Miller's anatomy of the dog, $3^{\text {rd }}$ edn. pp. 894-952. Philadelphia: WB Saunders.

2. Assheuer, J. and Sager, M. (1997) MRI and CT atlas of the dog, Cambridge: Blackwell Scientific. 
3. Warwick, R. and Williams, P. (1973) Gray's anatomy of the human body, $29^{\text {th }}$ edn. Philadelphia: Lea and Febiger.

4. De Lahunta, A. (1983) Veterinary neuroanatomy and clinical neurology, 2nd edn. London: WB Saunders.

5. De Lahunta, A. and Glass, E. (2009) Veterinary neuroanatomy and clinical neurology, 3rd edn. St. Louis: Elsevier Saunders.

6. Wilder, B. (1880) The cerebral fissures of the domestic cat. Felis domestica. Science 1, 49-51.

7. Kraft, SL.; Gavin, PR.; Wendling, LR. and Reddy, VK. (1989) Canine brain anatomy on magnetic resonance images. Veterinary Radiology 30, 147-158.

8. Schaller, O. (1992) Illustrated veterinary anatomical nomenclature, Stuttgart: Verlag.

9. Gavin, PR. and Bagley, RS. (2009) Practical small animal MRI, 1st edn. Ames: Wiley-Blackwell.

10. Weidenreich, F. (1941) The brain and its role in the phylogenetic transformation of the human skull, Philadelphia: American Philosophical Society.

11. Tapp, P.; Siwak, C.; Gao, F.; Chiou, J.; Black, S.; Head, E.; Muggenburg, B.; Cotman, C.; Milgram, N. and Su, M. (2004) Frontal lobe volume, function, and B-amyloid pathology in a canine model of aging. Journal of Neuroscience 24, 8205-8213.

12. Bianchi, L. (1895) The functions of the frontal lobes, London: Macmillan.

13. Drees, R.; Forrest, L. and Chappell, R. (2009) Comparison of computed tomography and magnetic resonance imaging for the evaluation of canine intranasal neoplasia. Journal of Small Animal Practice 50, 334-340.

14. Dhaliwal, R.; Barbara, E.; John, M.; Igor, V. and Clarkson, R. (2004) Subjective evaluation of computed tomography and magnetic resonance imaging detecting intracalvarial changes of canine nasal neoplasia. International Journal of Applied Research in Veterinary Medicine 2, 201-208.

15. George, T. and Smallwood, J. (1992) Anatomic atlas for computed tomography in the mesaticephalic dog: Head and neck. Veterinary Radiology \& Ultrasound 33, 217-240.

16. Gottfried, J. and Zald, D. (2005) On the scent of human olfactory orbitofrontal cortex: meta-analysis and comparison to non-human primates. Brain Research Reviews 50, 287-304.

17. Lee, D.; Cho, H. and Cho, Y. (2007) Typical carcinoid tumor of the nasal cavity. Auris Nasus Larynx 34, 537 539.

18. Anderson, W.; Anderson, B. and Smith, B. (1994) Atlas of canine anatomy, Philadelphia: Lea and Febiger.

19. Kraft, SL.; Gavin, PR.; Wendling, LR. and Reddy, VK. (1989) Canine brain anatomy on magnetic resonance images. Veterinary Radiology 30, 147-158.

20. Leigh, E.; Mackillop, E.; Robertson, I. and Hudson, L. (2008) Clinical anatomy of the canine brain using magnetic resonance imaging. Veterinary Radiology \& Ultrasound 49, 113-121.

21. Fletcher, TF. (1993) Spinal cord and meninges. In: Miller, M., (Ed.) Miller's anatomy of the dog, 3rd edn. pp. 800-828. Philadelphia: WB Saunders.

22. Kaufman, HH.; Cohen, G.; Glass, TF.; Huchton, JD.; Pruessner, JL.; Ostrow, PT.; Andia-Waltenbaugh, A. and Dujovny, M. (1981) CT atlas of the dog brain. Journal of Computer Assisted Tomography 5, 529-537.

23. Langley, J. (1883) The structure of the dog's brain. Journal of Physiology 4, 248-326.

24. Smith, B. (1999) The brain and associated structures, Nieginski, USA: Nieginski.

25. Budras, K.-D.; McCarthy, P.; Fricke, W. and Richter, R. (2002) Anatomy of the dog, Hannover: Schlütersche Verlagsbuchhandlung.

26. Evans, H. (1993) The skeleton. In: Miller, M., (Ed.) Miller's anatomy of the dog, 3rd edn. pp. 122-218. Philadelphia: WB Saunders. 